\title{
O NOVO NIILISMO NA ATUAL LITERATURA GERMÂNICA
}

Mansueto Kohnen, O. F. M.

E realmente difícil encontrar algo essencialmente nôvo nas Letras Contemporâneas. Também os pretensos niilistas, materialistas e ateístas ressuscitam, de quando em vez, anunciando com grande alarido que inventaram a pólvora, que criaram uma nova moda - mas apenas moda.

A onda dos niilistas dos primeiros decênios do século corrente ostentou os nomes de Robert Walser (1878-1956), Franz Kafka (1883-1924), Ernst Juenger, nascido em 1895, Gottfried Benn (1886-1956) e Eugen Gottlob Winkler (1912-1936), como demonstramos em nosso Estudo intitulado "A moderna Literatura Germânica ao encontrar-se com o nada", em Verbum, T. XVIII, Fasc. 3-4, 1961, 309-337 e em nossa "História da Literatura Germânica", Vol. IV, Cap. VI, Editôra Vozes, 1963.

Mal e mal se faz o esfôrço de esquecer ou menosprezar esta onda nilista e já surge outra tentativa de prender a atenção dos ávidos de sensação no domínio das atuais letras germânicas. Esste niilismo naturalmente não traz nada de nôvo no que diz respeito à essência, porque sua pobreza interior é incontestada. Tenta confabular algo sôbre temas, estilos e tendências novas. Sim, tendências! A palavra não é nossa, mas foi lançada por um dos principais corifeus dêste novo niilismo, como logo mais veremos. Porém, tôda e qualquer arte, inclusive a arte literária, que pretende cultivar tendências de qualquer jaez, seja niilista, confessional, racista, politica, filosófica, etc., condena a si própria. Não é capaz de sair do círculo vicioso da esterilidade de puro "L'art pour l'art" ou como St. George preconizava: "kunst fuer die kunst" (na sua grafia voluntariosa). 
A tendência niilista não é nada de nôvo nas letras. Existiu, existe e existirá, em tôdas as ramificações literárias. Foi cultivada, p. ex. nas letras germânicas, por Folz e os demais autores das farsas carnavalescas dos séculos XIV e XV, como exceção louvável de Hans Sachs. A mesma tendência vive nas obras de Crébillon e Sade antes da Revolução Francesa. E os niilistas do século XIX (MarX, Engels, Bakunin) e dos primeiros decênios do nosso século criaram mais catástrofes do que por exemplo as situações sociais de muitos países. Tiraram, muitas vêzes, aos govêrnos estatais e à sociedade humana a fôrça interior, vivendo numa discussão ininterrupta entre luz e trevas. Manifestaram, após poucos anos, a destruição misteriosa das almas, envenenando o próprio povo.

Não deixa de ser um fato alarmante, que nas atuais letras germânicas começam a aparecer os princípios de um nôvo niilismo. Um dos seus centros é incontestavelmente o assim chamado "Grupo 47". A designação deriva-se do fato, que um grupo de literatos se reuniu no ano de 1947, portanto dois anos após o término da segunda guerra mundial. Esste grupo 47 congregou, inicialmente, qualquer número de literatos ou poetas, sem considerar sua escola ou corrente literária ou artística, sua orientação política, confessional, filosófica, sem impor ou apregoar programas, sem cacique ditatorial, sem tendência. As individualidades podiam desabrochar livremente, agir e escrever conforme seu impulso exterior e interior. Portanto, a coisa mais idealista dêste mundo!

Este círculo detestava virilmente qualquer ditadura literária depois de tantos anos de arte "dirigida" pelos déspotas nazistas. Tôdas as tendências, todos os estilos, tôdas as correntes literárias tinham os mesmos direitos. Quem nos informa sôbre êstes fatores é Walter Jens em sua obra "Deutsche Literatur der Gegenwart" (1961).

Estas foram as metas iniciais do grupo 47, quer dizer há uns 14 anos até a publicação (1961) do estudo de Jens. Mas estas metas deslocaram-se pouco a pouco. E hoje êste grupo 47 começa a ocupar uma posição poderosa, sim, de poder pronunciado, na vida espiritual germânica. Começa a impôr-se como fôrça secretamente totalitária, não de tendência direitista, mas justamente esquerdista-niilista. 
Não se conseguiu ainda a equiparação total de todos os componentes do grupo 47. Nem acreditamos que todos se submetam, pois os valores individuais de alguns literatos, em forma e fundo, divergem muitíssimo. Porém, as seduções das ditaduras - a História o provou e o continua a provar! são tremendas e lamentàvelmente muitas vêzes eficientes. $E$ então o chôro vem tarde...

Fazem parte dêste grupo 47 Hans Werner Richter, o anfitrião das reuniōes literárias, Alfred Andersch, Wofldietrich Schnurre, Walter Jens, Heinrich Boell, Ingeborg Achmann, Guenter Eich, Ilse Aichinger (austriaca e mulher de Eich), Ernst Schnabel, Siegfried Lenz, Martin Walser, Guenter Grass, Hans Magnus Enzenberger, Walter Hoellerer, Paul Celan, Wolfgang Hildesheimer, Uwe Johnson, Heinz von Cramer e outros.

Estudamos vários dêstes homens de letras em nosso IV volume da "História da Literatura Germânica", a saber: $H$. Boell, p. 323-326, G. Eich, p. 346-347, Celan, p. 351-352, Schnurre, p. 352, I. Aichinger, p. 352-353, W. Jens, p. 353, I. Bachmann, p. 358-359, E. Schnabel, p. 362-363.

É interessante lembrar aqueles, que não figuram entre os representantes do grupo 47 . Bem, em primeiro lugar, nenhum dos literatos vivos, que estudamos no capitulo VII da nossa "História da Literatura Germânica" e que nos deram sua "Poesia criada do Espírito Cristão". São nada menos do que 34 os autores estudados, dos quais grande parte ainda vive. Também dos elementos jovens, que criaram sua obra inspirada pelo Espírito Cristão, não encontramos alma viva no grupo 47 por não serem niilistas. Se fôr apenas questão de idade poderiam conviver com os citados no grupo 47, por exemplo: Werner Bergengruen, Manfred Hausmann, Josef Martin Bauer, E. Peterich, Ruth Schaumann, Marie Luise Kaschnitz, H. E. Holthusen, Albrecht Goes, Stefan Andres, Hubert Neufeld, Edzard Schaper, Luise Rinser e Lavant-Thonhauser. Portanto, os criadores do espírito cristão estão ausentes. Será que o grupo 47 se qualifica por si próprio?

Ainda mais: mesmo entre os autores digamos não cristãos deixaram de participar do grupo 47 homens literatos 
como W. Lehmann, Fr. G. Juenger, Csokor, E. Kaestner, H. Johst, Thiess, Gerd Gaiser, Kasack, Zuckmayer, Nossack, Hochwaelder, Frisch, Duerrenmatt, Krolow e outros. Por que não querem participar do nôvo niilismo, inicialmente tão livre, espontâneo? Temeram a posterior ausência de autêntica liberdade artística? Farejaram o advento de dias rubros e perigosos para a liberdade do espírito? Recuaram ante o curral estreito que lhes proibe a vivência da plena universalidade?

Um dos mais vivos e um dos maiores ativistas do grupo 47 é Walter Jens, catedrático de filologia antiga na universidade de Tuebingen. Tornou-se conhecido graças às suas novelas, alguns romances e mormente às muitíssimas críticas literárias. Justamente estas últimas evidenciam, cada vez com maior nitidez, principalmente na parte político-cultural e literária, que Jens anuncia um mundo completamente ateista, cujo âmago é o homem autônomo. E Jens é ouvido e admirado, pois, tôdas as quintas feiras realiza preleções, em Tuebingen, sôbre "Problemas da moderna Literatura Germânica". Seu auditório conta com mais de 1.000 (hum mil) de ouvintes entusiasmados. Sinais do tempo moderno!

O germanísta Jens fez, em 1960, durante a Feira de Livros de Frankfurt, uma conferência muito aplaudida, em que se queixava de que os poetas e escritores hodiernos não cuidam das preocupações e dos problemas de nossa época. Solenemente proclamou estar a favor da exposição dos problemas "positivos", se bem que o poeta deva também lembrar as negativas. A maior parte das revistas e dos jornais, também os cristãos, reproduziram as passagens mais marcantes do discurso de Jens, festejando antecipada e precipitadamente o regresso do filho pródigo.

Porém, desde que o ditador da outra margem do Danúbio e o representante das fôrças niilistas do Maligno fantasiou de "cristianismo positivo", conseguindo enganar milhões de cristãos em terras germânicas, ficamos desconfiados com graves razões. O positivo, a luz, pode ser fàcilmente distinguido do negativo e obscuro. Jens usa também o têrmo positivismo em sua obra citada, usando-o no sentido materialista em oposição às idéias. 
Jens lança, em contraste com a mentalidade e espiritualidade germânicas, a importância quase exclusiva do "Como" da representação literária em desfavor do "Que". A forma é tudo para êle, uma vez que admite absorver e deturpar a verdade pela inverdade destruidora e niilista.

Crítica literária, que cuida simultaneamente de forma, personalidade poética e fundo, não é - para Jens - critica artística. Assim, o crítico à la Jens tem a liberdade de afirmar, blaterar, discursar, negar à vontade. Só interessa o "Como" e o caminho para o diletante está aberto e desimpedido. Pois, o manejo abstrato e técnico da arte, que se encontra p. ex. nas obras de Joyce ou Th. Mann, é apenas forma morta. Em todo caso, Jens e seus amigos cultivam uma oposição suspeita em relação aos poetas realmente grandes do passado. $\mathbf{E}$ êstes afirmaram, que êles, ao criarem uma obra de arte, buscaram em primeiríssimo lugar o "Que", a idéia criadora, o assunto dinamisador. E se o "Que" enchia e dominava totalmente o coração, êle não tardava de encontrar a forma artística condigna. Gentileza, sr. Jens, consultor Goethe!

Jens é profesosr de filologia antiga, que requer um método científico rigoroso e exato, como o provam Lachmann, Moser e tantos outros em nossos dias. Filólogos e humanistas hauriram da sabedoria da antiguidade. Suas cognições se tornaram férteis, quando se aprofundaram nos fatos dos sábios. A moderna literatura niilista de Jens e amigos desconhecem tal atitude. Conhece apenas paralelos espirituosos. É, certamente, inteligente. Tem idéias, pensamentos e afirmações inesperadas. Não cansa. Sua memória é admirável. É o "Fuehrer" nato dos niilistas. Mas falta-lhe a autêntica cultura universalista. Prova-o sua "literatura germânica do presente, temas, estilos e tendências". Jens denomina esta sua obra, que parcialmente informa muito e muito bem e onde a gente até aprende bastante sem ter a obrigação de com tudo concordar, o próprio Jens intitula esta sua obra de tratado e de panfleto. $\mathbf{E}$ êle tem razão, porque é tendenciosamente niilista.

Mas Jens apenas é um sintoma. Não se trata só de sua obra, de sua pessoa. Êle representa na atual literatura germânica uma corrente, um verdadeiro movimento, a maior parte dos participantes do grupo 47. Êle tem numerosos amigos e 
companheiros, certamente não só em plagas germânicas, que cultivam ardentemente $o$ evangelho niilista.

O grupo 47 tem em Jens seu porta-voz. Tem afirmações céticas a respeito do cristianismo. Fala do "idilio cristão" qual Blunck redivivo. Fantasia da "união macabra de bomba e de cruz". O "positivo" - no sentido do discurso de Frankfurt é uma praça carnavalesca da mediocridade. Bondade e bom comportamento são privilégios dos medíocres. O dogmatismo liberal de Jens é mais vivo.

Temos a impressão que Jens e seus adeptos carecem de antenas para poder captar os grandes poetas e as poesias cristãs de nossos dias. Quem faz parte dos niilistas novos, a que Jens pertence, perde a suscetibilidade e a compreensão das polaridades e das decisões, que o encontro cristão com o mundo exige. Perde a possibilidade de poder compreender o poeta cristão que tenta descrever e criar poèticamente êste combate. Ninguém negará, que houve, há e haverá também mediocridade nesta tentativa. Mas mediocridade não é só nosso monopólio. Será que ela não viverá, mais acentuadamente ainda, no domínio das literaturas acristãs? anti-cristãs? niilistas?

Que recomendam Jens e seus amigos? Que defendem? Defendem Guenter Grass, Arno Schmid, Uwe Johnson, representantes inegáveis de um duvidoso lusco-fusco. O grupo 47 ou ao menos alguns dos representantes são apadrinhados, nos elementos formais, por Joyce, Durell ou Wolfe. Também Heinrich Boell, o poeta do meio ambiente burguês de Koeln, que mostra grande maestria e habilidade no uso dos novos meios épicos, é uma das grandes esperanças do grupo. No entanto, Boell contenta-se em descrever o vazio ambiente burguês, sem a indispensável criatividade poética.

A maioria das obras dêsses autores não conhece um conleúdo problemático e também uma arte problemática. Não haverá ninguém que queira negar por exemplo a grande habilidade lingüística de um Grass. Mas ela é apenas talento nalural, carecendo de disciplina e moderação para ser autêntica arte. Jens e seus amigos procuram emprestar ênfase e obter repercussão e propaganda para tais talentos. Naturalmente perdem, nesta propaganda, o sentido pela verdadeira gran- 
deza literária da mercadoria oferecida. Quem se escravizar ao espírito agressivo do grupo, é exaltado até às maiores alturas.

Jens e seus amigos formam uma pseudo-avant-garde da crítica niilista. Também outros - Sieburg, Bloecker e o maleável Karl Korn - foram tocados pela mesma tendência. Querem ser avantgardistas niilistas em 1961, esquecendo que os artistas de 1910 já o pretendiam ser.

Se há escritores germânicos da atualidade, que não desejam acompanhar o niilismo contemporâneo, também há críticos que não o fazem. Os suiços sóbrios e afamados, como Rychner ou Werner Weber, recuam diante dos abismos niilistas. Também críticos, que haurem da criatividade artistica do espírito cristão, como sejam Ragelstange, Karl August Horst e principalmente o excepcional Curt Hohoff, não conseguem oferecer louros aos "heróis" niilistas.

Há gente que se admira que os nillistas atuais tentam impressionar e pressionar não só a juventude acadêmica, mas através de livros didáticos até os próprios ginasianos. Não nos admiramos, pois êles são mais lógicos e conseqüentes em sua destruição negativa do que por exemplo os pseudo-cristãos, que fogem das derradeiras conseqüências lógicas de sua atitude artística e literária. Jens e os seus combatem abertamente os programas didáticos da Baviera católica. Praticam a crítica e educação literárias de niilistas. Acentuam a crítica orientada pela sua ideologia. São dogmáticos e intolerantes até o extremo, porque a crítica niilista da arte é, para êles, expressão de sua total cosmovisão. Mas êste dogmatismo e esta intolerância encontramos em quase todos os domínios acristãos ou anti-cristãos, não só nas terras germânicas da atualidade. Êles são aplaudidos até em nosso meio.

Jens e seus adeptos perseguem, mormente em "Die Zeit", os autores de livros didáticos, que são imbuídos do espírito cristão. Uma das vítimas mais sacrificadas é Georg Ried com as obras "Wesen und Werden der deutschen Dichtung von den Anfaengen bis zur Gegenwart" (Muenchen 1961) e sua "Weltliteratur unserer Zeit" (Ibid. 1961). Companheiro barato dessa atitude é, em nosso meio, por exemplo o histérico 
racista semita O. M. Carpeaux, Herr Karpfen, que G. Bernanos chamou de "kleiner Setzkarpfen", que gosta de trabaIhar no lôdo e na lama. Também os "Jenses" recusam apaixonada e violentamente em "Die Zeit" (29 de dez. de 1961) os dois volumes do famoso dicionário de literatura, de orientação cristã, da mundialmente famosa Editôra Herder. As razões são claras: imbecilidade dogmática de totalitários niilistas.

Que fazer à vista destas atitudes? Reexaminar e aprofundar nosso julgamento e confessá-los ante os ataques dos adversários.

Depois: não silenciar os perigos do novo nilismo, cuja vanguarda já iniciou a luta. A obra de $\mathrm{H}$. Bacht: "Weltnaehe oder Weltdistanz?" (Frankfurt 1962) acentua, ao interrogar se devemos aproximar ou distanciar-nos do mundo atual, que a aparente paz depois de 1945 passou, transformando-se em angústia dos homens da atualidade. Sabe, que uma evolução espiritual está em marcha. Os diálogos entre grupos e partidos tornam-se mais violentos e mais duros. A atualidade (literária) quer novamente sublinhar os elementos separatistas, a contradição e a discussão. O nôvo niilismo não pára e avança com violência ditatorial.

O que fôr apenas moda neste nôvo niilismo passará ràpidamente. Como desapareceu quase de repente St. George! E o atual desprestígio de $R$. M. Rilke veio inesperadamente. Ao contrário, descobre-se o valor da arte, como ela foi praticada com fidelidade em relação a si própria e ao mundo. Aprecia-se novamente a arte e a grandeza de um Hofmannsthal, sendo a obra do austríaco temporàriamente considerada pelos niilistas qual "Poesia dos Ricos" e que é, no fundo e na forma, arte para todos.

Discussões espirituais não são ligadas, como as guerras, a determinadas datas. Elas perduram. À vista disso é importante, despertar na juventude espiritualmente aberta, o senso pela verdadeira grandeza artística. A onda niilista não pode satisfazer à geração nova. Ela pede valores e critérios objetivos da arte literária. 
As tentativas críticas dos nilistas exigem, do outro lado, nosso exame de posição. A pura ciência empolada não satisfaz e não pode pedir nossa capitulação, quando procede de grupinhos niilistas. Assim já o fêz Hans Egon Holthusen (Cfr. Die Tat, Zuerich, ql X 1961) ao analisar e discutir a obra citada de Jens. E não temeu e não recebeu desmentido substancial. O mesquinho e estreito niilismo empalidece, finalmente, ante a grande luminosidade e riqueza integral do universalismo da poesia e literatura universalistas. 